\title{
Disparities in ventilatory and circulatory responses to bicycle and treadmill exercise ${ }^{1}$
}

\author{
Manfred Niederberger, ${ }^{2}$ Robert A. Bruce, Fusako Kusumi, and Shirley Whitkanack \\ From the Department of Medicine, Division of Cardiology, \\ University of Washington, Seattle, U.S.A.
}

Haemodynamic and ventilatory responses, during multilevel bicycle exercise and during multilevel symptomlimited treadmill exercise, were compared in 8 patients with coronary heart disease and in one sedentary middle-aged man, at known percentages of each subject's maximal oxygen uptake ( $\dot{V} \mathrm{O}_{2}$ max), determined on $a$ treadmill.

When comparisons were made at the same percentages of $\dot{V} o_{2}$ max on treadmill or bicycle, we found higher arterial mean pressure, heart rate, pressure-rate product, peripheral vascular resistance, and pulmonary ventilation during bicycle exercise. Cardiac output was the same and stroke volume was lower on the bicycle.

We conclude that in terms of arterial blood pressure and pressure-rate product, all conditions being as mentioned above, bicycle exercise constitutes a greater stress on the cardiovascular system at any given oxygen uptake than does treadmill exercise.

The mechanism of the observed differences in the responses to the two types of exercise may reflect potentiation of normal reflexes initiated by working muscles when arterial inflow is impeded by more vigorous contractions, especially in individuals not conditioned for bicycling. The clinical importance of these findings in relation to the evaluation of exercise performance of patients with cardiovascular disease is that slightly higher values of $\dot{V}_{2}$ max are achieved with slightly less haemodynamic stress on the diseased left ventricle with treadmill exercise.

Inasmuch as normally there are greater circulatory and ventilatory responses to bicycle exercise in terms of heart rate and pulmonary ventilation at submaximal exercise and in terms of blood pressure at maximal exertion (Hermansen, Ekblom, and Saltin (1970), yet lower limits of oxygen uptake $\left(\mathrm{VO}_{2}\right)$ and cardiac output $(\dot{Q})$ than are observed with treadmill exercise (Åstrand and Saltin, I96r; Hermansen and Saltin, 1969; Hermansen et al., 1970; Miyamura and Honda, 1972), there is a legitimate question as to which method imposes the greater stress on cardiovascular patients. This problem is particularly relevant to those patients who develop myocardial ischaemia on exertion, whether in the context of exercise stress testing or of exercise conditioning for cardiac rehabilitation.

Received 12 November 1973.

- 1 This study has been supported in part by a Program Project Grant from National Heart and Lung Institute, National Institutes of Health, and a grant from the National Institutes of Health, and by a Poncin Scholarship from the Seattle First National Bank.

${ }^{2}$ Max Kade Foundation Fellow from Kardiolog. Univ. Klinik, Vienna, Austria.
This study was designed to compare the haemodynamic responses, primarily of patients with coronary heart disease, to bicycle and treadmill exercise performed within one to two hours. In order to obtain valid comparisons, data were selected from a series of observations to represent responses to exercise on both bicycle and treadmill with similar relative aerobic requirements, or percentages of highest possible oxygen uptake $\left(\mathrm{V}_{2} \mathrm{max}\right)$ for each person.

\section{Subjects and methods}

Physical and clinical characteristics of I normal middleaged man and 8 patients with coronary heart disease are shown in Table I. None of the subjects had valvular heart disease, was anaemic, or had evidence of pulmonary disease by chest $x$-ray and pulmonary functional screening tests. None of them suffered from intermittent claudication or from skeletomuscular disease limiting exercise performance. None was treated with digitalis or beta-blocking agents for at least two weeks before the study. Physical activity status was defined as active if the 
TABLE I Physical and clinical characteristics

\begin{tabular}{|c|c|c|c|c|c|c|c|c|c|}
\hline \multirow[t]{2}{*}{$\begin{array}{l}\text { Subjects } \\
\text { (men) }\end{array}$} & \multirow[t]{2}{*}{ Diagnosis } & \multirow[t]{2}{*}{$\begin{array}{l}\text { NYHA } \\
\text { class }\end{array}$} & \multirow[t]{2}{*}{$\begin{array}{l}\text { Activity } \\
\text { status }\end{array}$} & \multirow[t]{2}{*}{$\begin{array}{l}\text { Age } \\
(y r)\end{array}$} & \multirow[t]{2}{*}{$\begin{array}{l}\text { Height } \\
(\mathrm{cm})\end{array}$} & \multirow[t]{2}{*}{$\begin{array}{l}\text { Weight } \\
(k g)\end{array}$} & \multirow{2}{*}{$\begin{array}{l}\text { Relative } \\
\text { weight } \\
(\%)\end{array}$} & \multicolumn{2}{|c|}{$\begin{array}{l}\text { Blood pressure at rest } \\
(\mathrm{mmHg})\end{array}$} \\
\hline & & & & & & & & Systolic & Diastolic \\
\hline $\mathbf{I}$ & Normal & I & Sedentary & 59 & 182 & $83 \cdot 2$ & 100 & 128 & 96 \\
\hline 2 & ASHD, post SVG & I & Active & 63 & 170 & 65.9 & 90 & 160 & 105 \\
\hline \multirow{4}{*}{$\begin{array}{l}3 \\
4 \\
5 \\
6\end{array}$} & ASHD, HMI, post SVG & III & Active & 60 & 174 & $69 \cdot I$ & 90 & 130 & 72 \\
\hline & ASHD, HMI, AP & I & Sedentary & $4 I$ & 183 & $79 \cdot 5$ & 95 & 126 & 86 \\
\hline & ASHD, HMI, AP & III & Sedentary & 50 & 178 & $70 \cdot 4$ & 80 & 130 & 100 \\
\hline & ASHD, HMI, essential & IV & Active & 50 & 56 & & & & \\
\hline \multirow{2}{*}{$\begin{array}{l}7 \\
8\end{array}$} & ASHD, post SVG & I & Active & 40 & 180 & $\begin{array}{l}00 \cdot 4 \\
88 \cdot 2\end{array}$ & 108 & 132 & 80 \\
\hline & ASHD, 2 HMI, post SVG & II & Active & 58 & I 70 & $71 \cdot 8$ & 98 & I 88 & 90 \\
\hline \multirow[t]{2}{*}{9} & ASHD, HMI, AP & I & Sedentary & 49 & 170 & $62 \cdot 3$ & 85 & 130 & 80 \\
\hline & & & & $52 \pm 8$ & $174 \pm 8$ & $73 \cdot 0 \pm 8 \cdot 7$ & $95 \pm 8$ & $144 \pm 23$ & $90 \pm$ I I \\
\hline
\end{tabular}

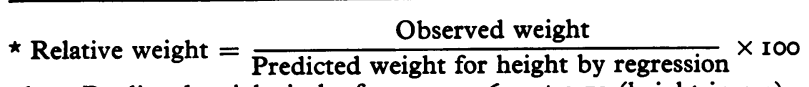

where Predicted weight in $\mathrm{kg}$ for men $=60 \cdot 7+0 \cdot 79$ (height in $\mathrm{cm}$ ).

Abbreviations: AP angina pectoris; ASHD atherosclerotic heart disease; HMI healed myocardial infarction; SVG saphenous vein grafting.

subjects performed exercise strenuous enough and long enough to cause sweating regularly at least once a week (McDonough, Kusumi, and Bruce, 1970). All subjects performed a control treadmill test (Bruce, Kusumi, and Hosmer, 1973), usually on the day before the haemodynamic studies. Functional aerobic impairment was derived from the duration of this control test by use of nomograms, taking age, sex, and physical activity status into account. After explanation of the test and signed informed consent, a Swan-Ganz catheter (French size 7) was placed through a left cubital vein into a pulmonary artery and a 'teflon' catheter was inserted into the left radial or brachial artery by the Seldinger technique. Pressures were recorded by use of the same Statham pressure transducers $\left(\mathrm{P}_{23} \mathrm{~Gb}\right.$ for systemic and $\mathrm{P}_{23} \mathrm{~V}$ for pulmonary arterial pressures), and mean pressures were derived by electrical averaging. The zero pressure reference level was adjusted at the height of the anterior fourth intercostal space in the upright position; as the gradient of the treadmill increased, it was moved upward with the subject.

The tracing of a bipolar transthoracic electrocardiographic lead (Bruce, I97I) was continuously displayed on a scope, together with both systemic and pulmonary arterial pulsatile pressures. Heart rate was obtained from an electrocardiographic tracing recorded at $25 \mathrm{~mm} / \mathrm{sec}$ paper speed. ST segment depression was also defined visually from this tracing; depression of more than 0.1 $\mathrm{mV}$ for $0.06 \mathrm{sec}$ of the segment was considered abnormal. Cardiac output (Q) was estimated by the direct Fick method. $\mathrm{Vo}_{2}$ was measured from $\mathrm{r} 8 \mathrm{o} \mathrm{sec}$ samples of expired air breathed into evacuated neoprene bags at rest and from $60 \mathrm{sec}$ samples during exercise. Arterial mixed venous oxygen difference $\left(\mathrm{AV} \mathrm{O} \mathrm{O}_{2} \mathrm{D}\right)$ was calculated from the oxygen contents, measured by use of a LEX-O $-\mathrm{CON}$ (Kusumi, Butts, and Ruff, 1973), of arterial and mixed venous blood (sampled from the brachial or radial and from the pulmonary artery). After placement of the catheters, the subjects (except one, who performed the treadmill test first) were seated on a Monark bicycle ergometer. Saddle height was adjusted as chosen by the subject. The subjects were allowed to hold the handlebars with both hands, but were cautioned against a strong handgrip.

Lowest workload and increases in workload were adjusted to the circulatory and physical capacity of each subject, as evaluated during the control treadmill test, in order to obtain at least four measurements within the subject's functional limits. Thus, the rates of increase in workload ranged from 12.5 to 50 watts.

Each workload was kept constant for 4 minutes, except the highest workload which was usually terminated after 3 minutes. Measurements were taken at rest, while pedalling against $O$ watts, in the last minute of each workload and in the last 2 to 3 minutes of exercise. After an hour of supine bed rest, the subjects performed a multilevel symptom-limited treadmill test. Six subjects started at stage $\mathrm{I} / 2$ ( $1 \cdot 7 \mathrm{miles} / \mathrm{hr}, 5 \%$ gradient) and 3 started at stage I (I.7 miles $/ \mathrm{hr}$, Io $\%$ gradient). Thereafter the test followed the standardized procedure as described (Bruce et al., 1973). Measurements were taken while standing at rest, in the last minute of each stage, and in the last 2 to 3 minutes of exercise. Durations of these treadmill tests are not comparable with those of the control treadmill tests because the patients could rest some weight on an arm support, necessary to keep the catheterized arm in a steady position. After completion of the treadmill test, the catheters were removed and the subjects were kept under medical supervision for at least two hours and were then discharged from the hospital. No complications occurred.

The data were analysed with reference to per cent $\dot{\mathrm{Vo}}_{2} \mathrm{max}$, which expresses absolute $\dot{\mathrm{VO}}_{2}$ as a percentage of the highest $\hat{\mathrm{V}}_{2}$ observed during maximal treadmill 
TABLE 2 Circulatory and electrocardiographic responses to maximal exercise (treadmill)

\begin{tabular}{|c|c|c|c|c|c|c|c|c|c|c|}
\hline Subjects & $\begin{array}{l}\text { Dura- } \\
\text { tion } \\
(\mathrm{sec})\end{array}$ & $\begin{array}{l}\text { Func- } \\
\text { tional } \\
\text { aerobic } \\
\text { impair- } \\
\text { ment }(\%)\end{array}$ & $\begin{array}{l}\dot{\mathrm{V}}_{\mathrm{O}_{2}} \max \\
(\mathrm{ml} / \min )\end{array}$ & $\begin{array}{l}\dot{\mathrm{V}}_{\mathrm{O}_{2}} \max \\
\mathrm{ml} / \\
(\mathrm{kg} \cdot \min )\end{array}$ & $\begin{array}{l}\text { Max. } \\
\text { heart } \\
\text { ratel } \\
\text { min } \\
\text { (beats) }\end{array}$ & $\begin{array}{l}\text { Change } \\
\text { in heart } \\
\text { ratel } \\
\text { min } \\
\text { (beats) }\end{array}$ & $\begin{array}{l}\text { Max. } \\
\text { systolic } \\
\text { blood } \\
\text { pressure } \\
(\text { mmHg })\end{array}$ & $\begin{array}{l}\text { Change } \\
\text { in systolic } \\
\text { blood } \\
\text { pressure } \\
(\mathrm{mmHg})\end{array}$ & $\begin{array}{l}\text { Max. } \\
\text { pressure } \\
\text { rate } \\
\text { product| } \\
\text { Ioo }\end{array}$ & $\begin{array}{l}S T \\
\text { depres- } \\
\text { sion }\end{array}$ \\
\hline & 420 & I4 & 2420 & $29 \cdot I$ & 160 & 65 & 212 & 84 & 339 & - \\
\hline 2 & 555 & -5 & 2001 & 30.4 & I75 & 93 & I66 & 6 & 290 & + \\
\hline 3 & 413 & I8 & I999 & 28.9 & I3I & $5 \mathrm{I}$ & I75 & 45 & 229 & + \\
\hline 4 & 416 & 36 & 2128 & $26 \cdot 8$ & 175 & 99 & 162 & 40 & 283 & + \\
\hline 5 & 401 & 30 & I6I6 & 23.0 & 180 & 84 & I 88 & 58 & 338 & + \\
\hline 6 & 450 & 25 & I97 I & $29 \cdot 7$ & 175 & 103 & 210 & 40 & 367 & + \\
\hline 7 & 628 & 15 & 3093 & $35 \cdot I$ & 190 & 120 & 204 & 72 & 387 & + \\
\hline 8 & 380 & 24 & 1713 & 23.9 & 160 & 102 & 180 & -8 & 287 & + \\
\hline \multirow[t]{3}{*}{9} & 428 & 34 & 1802 & 28.9 & 148 & 76 & 180 & 50 & 266 & + \\
\hline & 454 & 21 & 2083 & $28 \cdot 4$ & I 66 & 88 & I 86 & 43 & 310 & \\
\hline & \pm 82 & \pm I3 & \pm 447 & $\pm 3 \cdot 6$ & \pm 18 & $\pm 2 I$ & \pm 19 & \pm 29 & $\pm 5 I$ & \\
\hline
\end{tabular}

exercise. Statistical analysis used Students' paired t test. $P$ values larger than 0.05 were considered not significant.

\section{Results}

I) Responses to maximal exercise on treadmill (control test)

Maximal exercise elicited $\mathrm{Vo}_{2} \max$ of $2083 \pm 447 \mathrm{ml} /$ $\mathrm{min}, 28 \cdot 4 \pm 3.6 \mathrm{ml} / \mathrm{kg} \cdot \mathrm{min}$ ). Functional aerobic impairment of 14 per cent for the normal subject was well within the normal range, while the mean was 21 per cent for the entire group (Table 2).
Similarly, circulatory responses were typical of individuals with only mild functional aerobic impairment. All 8 patients exhibited horizontal or downsloping ST segment depression (<- $<.1 \mathrm{mV}$ ) after this exertion; the normal subject did not.

\section{2) Comparison of haemodynamic responses}

The major findings were that at all equivalent levels of $\dot{\mathrm{Vo}}_{2}$ and percentages of $\dot{\mathrm{Vo}}_{2}$ max, mean systemic arterial blood pressure $\left(\overline{\mathbf{P}}_{\mathrm{SA}}\right)$ and pressure

TABLE 3 Haemodynamic responses to upright exercise, bicycle vs. treadmill, mean values $\pm S D$

\begin{tabular}{|c|c|c|c|c|c|c|c|}
\hline \multirow[b]{3}{*}{ Type of exercise } & \multicolumn{2}{|l|}{ Rest } & \multirow{3}{*}{$\begin{array}{l}\begin{array}{l}\text { Pedalling } \\
\text { without } \\
\text { resistance } \\
\text { o watt }\end{array} \\
\text { Bicycle }\end{array}$} & \multirow{2}{*}{\multicolumn{2}{|c|}{$\begin{array}{l}\text { Workloads requiring } \\
40-60 \text { per cent } \dot{\mathrm{V}}_{2} \max \end{array}$}} & \multirow{2}{*}{\multicolumn{2}{|c|}{$\begin{array}{l}\text { Workloads requiring } \\
61-85 \text { per cent } \dot{\mathrm{V}}_{2} \max \end{array}$}} \\
\hline & \multirow{2}{*}{$\begin{array}{l}\text { (sitting) } \\
\text { Bicycle }\end{array}$} & \multirow{2}{*}{$\frac{\text { (standing) }}{\text { Treadmill }}$} & & & & & \\
\hline & & & & Bicycle & Treadmill & Bicycle & Treadmill \\
\hline $\begin{array}{l}\text { No. } \\
\text { Watts or stage }\end{array}$ & 9 & 9 & $\begin{array}{l}9 \\
0\end{array}$ & $\stackrel{9}{56+17}$ & $\stackrel{9}{I-r^{\prime}+r \cdot 6^{\prime} \star}$ & $\begin{array}{l}9 \\
06+27\end{array}$ & $\stackrel{9}{1 I-2^{\prime}+2 \cdot 0^{\prime}}$ \\
\hline $\begin{array}{l}\dot{\mathrm{V}}_{\mathrm{E}}(1 . / \mathrm{min}) \\
\end{array}$ & $8 \cdot 9 \pm 3 \cdot 1$ & $10 . \overline{8 \pm 4} .0$ & $10 \cdot 6 \pm 2 \cdot 1$ & $\begin{array}{c}50 \pm 17 \\
25 \cdot 8 \pm 7 \cdot 0\end{array}$ & $\begin{array}{l}1-1 \pm 1 \cdot 0 \\
22 \cdot 2 \pm 4 \cdot 3\end{array}$ & $\begin{array}{r}90 \pm 27 \\
46 \cdot 0 \pm 14\end{array}$ & $\begin{array}{l}11-2 \pm 2.0 \\
37.2 \pm 12.4 \dagger\end{array}$ \\
\hline$\dot{\mathrm{Vo}}_{2}(\mathrm{ml} / \mathrm{min})$ & $309 \pm 43$ & $348 \pm 63$ & $428 \pm 64$ & $1069 \pm 236$ & $1090 \pm 149$ & $1553 \pm 402$ & $1559 \pm 443$ \\
\hline Per cent $\dot{\mathrm{V}} \mathrm{O}_{2} \max$ & $15 \cdot 2 \pm 2 \cdot 9$ & $16 \cdot 9 \pm 3 \cdot 1$ & $2 I \cdot I \pm 4 \cdot 6$ & $5 I \cdot 5 \pm 4 \cdot 5$ & $52 \cdot 8 \pm 3 \cdot 5$ & $74 \cdot 1 \pm 8 \cdot 4$ & $74 \cdot 1 \pm 8 \cdot 2$ \\
\hline $\begin{array}{l}\text { AV } \mathrm{O}_{2} \mathrm{D}(\mathrm{ml} / \mathrm{l} .) \\
\dot{\mathrm{Q}}(\mathrm{l} . / \mathrm{min})\end{array}$ & $\begin{array}{r}70.9 \pm 5.9 \\
4.4 \pm 0.8\end{array}$ & $\begin{array}{c}77 \cdot 6 \pm 13 \cdot 6 \\
4 \cdot 6 \pm 1 \cdot 0\end{array}$ & $\begin{array}{r}77 \cdot 9 \pm 6.2 \\
5.5 \pm 0.8\end{array}$ & $\begin{array}{c}112 \cdot 6 \pm 9 \cdot 1 \\
9 \cdot 5 \pm 2 \cdot 0\end{array}$ & $\begin{array}{c}113 \cdot 7 \pm 12 \cdot 8 \\
9 \cdot 7 \pm 2 \cdot 1\end{array}$ & $\begin{array}{c}133.9 \pm 11.0 \\
11.6 \pm 2.8\end{array}$ & $\begin{array}{c}132 \cdot 3 \pm 14 \cdot 1 \\
11 \cdot 8 \pm 3 \cdot 0\end{array}$ \\
\hline HR (beats/min) & $83 \pm 17$ & $93 \pm 16 \ddagger$ & $87 \pm 12$ & $122 \pm 19$ & $113 \pm 12$ & $149 \pm 16$ & $137 \pm 19 \ddagger$ \\
\hline$\underline{S V}(\mathrm{ml})$ & $54 \pm 13$ & $50 \pm 15$ & $63 \pm 7$ & $78 \pm$ II & $86 \pm 17$ & $78 \pm 18$ & $85 \pm 16 t$ \\
\hline$\overline{\mathbf{P}}_{\mathrm{SA}}(\mathrm{mmHg})$ & $100 \pm 12$ & $102 \pm 10$ & $116 \pm 16$ & $128 \pm 2 I$ & III $\pm 14 \dagger$ & $147 \pm 19$ & $118 \pm 155$ \\
\hline$\overline{\mathbf{P}}_{\mathrm{PA}}(\mathrm{mmHg})$ & $12 \pm 2$ & $14 \pm 2 \ddagger$ & $16 \pm 3$ & $22 \pm 4$ & $23 \pm 3$ & $28 \pm 5$ & $25 \pm 4$ \\
\hline $\mathrm{PR} / 100$ & $87 \pm 19$ & $94 \pm \mathrm{r} 8$ & IOI \pm 19 & $157 \pm 43$ & $125 \pm 21 \ddagger$ & $220 \pm 43$ & $162 \pm 338$ \\
\hline Systemic resista & $2004 \pm 509$ & $1863 \pm 465$ & $1736 \pm 474$ & I $102 \pm 244$ & $958 \pm 263 \ddagger$ & $1078 \pm 334$ & $846 \pm 244 \oint$ \\
\hline
\end{tabular}

* Explanation of the $-S D$ is that some patients start with stage ' $I / 2$ ', i.e. -3 minutes.

$\dagger \mathrm{P}<0.01$. $\quad \ddagger \mathrm{P}<0.05$. $\quad \delta \mathrm{P}<0.001$ (paired $\mathrm{t}$ test).

Abbreviations: $\mathrm{AV} \mathrm{O}_{2} \mathrm{D}=$ arterial mixed venous oxygen difference; $\mathrm{HR}=$ heart rate; $\overline{\mathrm{P}}_{\mathrm{PA}}=$ mean pulmonary arterial pressure; $\mathrm{PR}=$ pressure rate product; $\dot{\mathrm{Q}}=$ cardiac output; $\overline{\mathrm{P}}_{\mathrm{SA}}=$ mean systemic arterial pressure; $\mathrm{SV}=$ stroke volume; $\dot{\mathrm{V}}_{\mathrm{E}}=$ total ventilation $; \dot{\mathrm{V}}_{2}=$ oxygen uptake; $\dot{\mathrm{V}} \mathrm{O}_{2} \mathrm{max}=$ maximal oxygen uptake. 


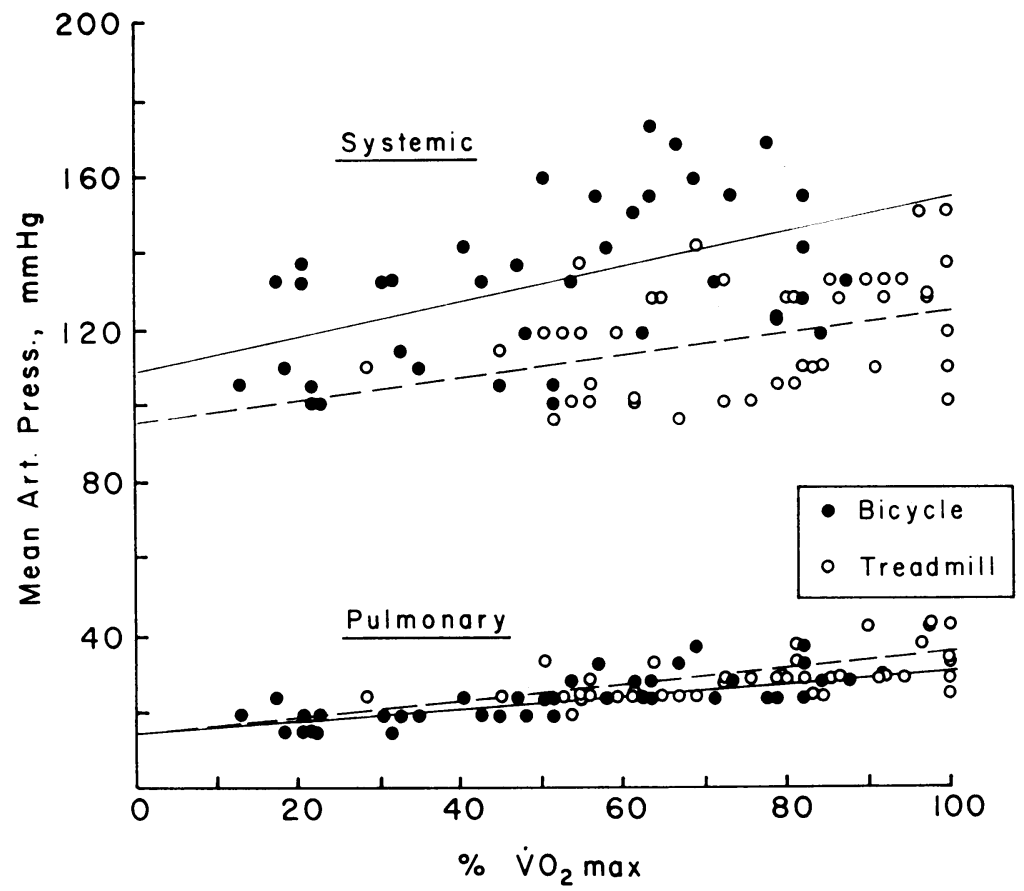

FIG. I Measurements during bicycle and treadmill exercise of mean systemic $\left(\bar{P}_{S A}\right)$ and mean pulmonary arterial pressures $\left(\bar{P}_{P_{A}}\right)$ plotted against per cent $\dot{V} o_{2}$ max. During bicycle exercise, all subjects had higher $\bar{P}_{S A}$ than at comparable $\dot{V O}_{2}$ on the treadmill.

Regression equations are $\bar{P}_{S A}:$ bicycle: $y=107+0.0479 x ;$ treadmill: $y=95+0.0310 x$;

$\bar{P}_{P A}:$ bicycle: $y=12+0.0202 x ;$ treadmill: $y=12+0.0198 x$.

rate product were higher during exercise on the bicycle than on the treadmill (Fig. I and 2).

Pertinent baseline haemodynamic data from sitting at rest on the bicycle and standing at rest on the treadmill before exercise are given in Table 3. Pedalling against zero resistance increased $\mathrm{VO}_{2}$ by 38 per cent and reduced pooling of blood in the legs. This lowest level of bicycle exercise caused a 25 per cent increase in cardiac output ( $\dot{Q})$, accounted for by increases of 16 per cent in stroke volume (SV) and of 5 per cent in heart rate, accompanied by a rise in mean pulmonary arterial pressure $\left(\overline{\mathbf{P}}_{\mathrm{PA}}\right)$ from 12 to $16 \mathrm{mmHg}$.

Exercise of moderate intensity with relative aerobic requirements of around 50 per cent $\mathrm{Vo}_{2} \max$ was associated with a tendency towards larger pulmonary ventilatory volumes on the bicycle (an average difference of $16 \%$ ). There were no differences in $\dot{Q}$ and $A V \mathrm{O}_{2}$ difference, but heart rate tended to be faster (8\%) and stroke volume was accordingly smaller on the bicycle. $\overline{\mathbf{P}}_{\mathrm{SA}}$, because of greater systemic resistance, and pressure rate product were 15 per cent and 26 per cent higher, respectively.
More strenuous exercise, eliciting around 75 per cent $\mathrm{VO}_{2} \max$, caused even greater differences, all of them statistically significant. Measurements of ventilatory volumes during bicycle exercise exceeded those during treadmill exercise by 24 per cent, of $\overline{\mathbf{P}}_{\mathrm{SA}}$ and systemic resistance by 25 per cent and 27 per cent respectively, and of heart rate by 9 per cent, while $\dot{Q}$ and $\mathrm{AV} \mathrm{O}_{2}$ difference were essentially the same, and stroke volume was 8 per cent smaller during bicycle exercise; pressure rate product, however, was 39 per cent greater during bicycle exercise.

\section{Discussion}

At all comparable submaximal workloads, requiring similar percentages of $\dot{\mathrm{VO}}_{2} \mathrm{max}$, bicycle exercise caused greater rise in $\overline{\mathbf{P}}_{\mathbf{S A}}$ than did treadmill exercise, accompanied by faster heart rate and by larger ventilatory volumes/minute. A sedentary middle-aged man with functional aerobic impairment of 14 per cent showed similar responses. The highest workloads on the bicycle were subjectively. felt by the patients to approach their working capacity, but the test protocol was not designed to 


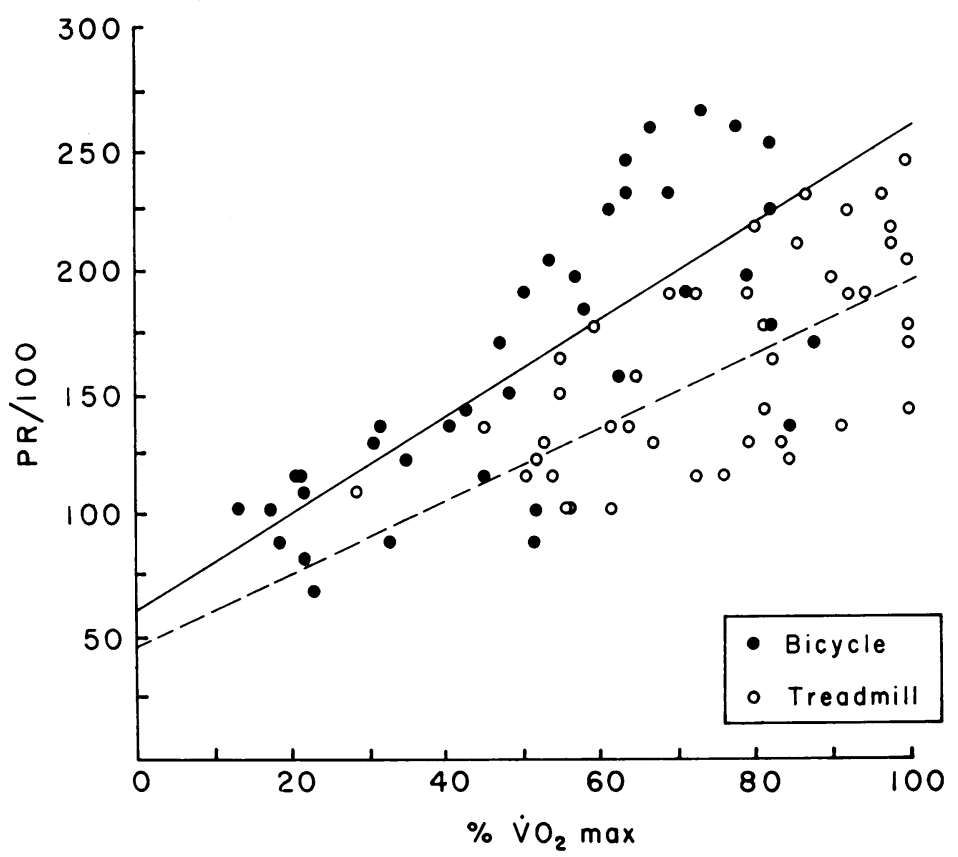

FIG. 2 Values for $P R / I 00$ versus per cent $\mathrm{VO}_{2}$ max. Regression equations are: bicycle: $y=60+0 \cdot 200 x$; treadmill: $y=48+0 \cdot 151 x$.

reach symptomatic limits on the bicycle. In some patients, however, haemodynamic measurements, such as $\overline{\mathbf{P}}_{\mathrm{SA}}$ and pressure rate product, obtained during such bicycle exercise, reached or slightly exceeded values obtained during maximal symptomlimited treadmill exercise.

The observed differences in $\overline{\mathbf{P}}_{\mathrm{SA}}$ measurements were not due to variations in adjustments of the zero pressure reference level, since similar pulmonary arterial pressures which were recorded during both forms of exercise remained the same. With one exception, the bicycle test was performed first, but repetition of such bicycle exercise in coronary patients does not result in different haemodynamic responses (Malmborg, 1965). Similarly, in a different group of coronary patients, we found satisfactory reproducibility of circulatory measurements when a multistage symptom-limited treadmill test was repeated after bed rest of $I-I \cdot 5$ hours (Niederberger et al., 1974).

Strenuous isometric muscle contraction, such as during handgrip, is associated with increased $\overline{\mathbf{P}}_{\mathrm{SA}}$ and other cardiovascular responses (Lind et al., 1964; Bruce et al., 1968; Siegel et al., 1972). For our subjects, this should not have been an important contributory factor, because we cautioned them to avoid any gripping of the handlebar, which may occur during strenuous bicycle exercise. If present at all, these factors should not have been more important than in the investigation of Hermansen et al. (1970), who found in 13 young normal men significant differences in $\overline{\mathbf{P}}_{\mathrm{SA}}$ between bicycle and treadmill exercise at maximal effort, but not at submaximal exercise levels. At submaximal levels, however, they also found a trend towards higher heart rate and lower stroke volume for the same $\dot{Q}$ on the bicycle, together with greater pulmonary ventilation.

Thus, there are similar qualitative differences between the two forms of exercise in normal young men and middle-aged men with coronary heart disease, but the magnitude of difference, at least in $\overline{\mathbf{P}}_{\mathrm{SA}}$, is greater in the latter. Explanations may lie in the pathophysiology of cardiovascular function in patients with ischaemic heart disease and with hypertension, but no direct attempt was made to answer specific questions in this regard. However, similar findings in one healthy, middle-aged man with only slightly raised diastolic blood pressure suggest normal circulatory regulation in our subjects. If the muscular pain in the muscles of the thighs, which usually occurred during bicycle exercise in our subjects, indicated high muscle tension and muscle ischaemia, then a possible explanation of their hypertensive and hyperventilatory responses is that these factors caused 
potentiation of normal reflex mechanisms originating from working musculature when arterial inflow is impeded (Asmussen and Nielsen, 1964; Lind et al., 1964).

However, greater $\overline{\mathbf{P}}_{\mathrm{SA}}$ responses on the bicycle were also measured in the absence of leg or thigh pain or before such pain developed. A possible explanation for differences between these measurements and the findings in young men (Hermansen et al., 1970) is that in our middle-aged men the leg musculature was not conditioned for bicycling, but was relatively well conditioned for walking. Therefore, during bicycling there was a greater strain on muscle groups or individual muscle fibres in the legs and this evoked increased stimuli for reflex mechanisms (Paterson, 1928; Coote, Hilton, and PerezGonzales, 1971). In contrast, on the treadmill the strain may have been more uniformly distributed over a greater mass of working muscles.

The data, in conclusion, indicate that in our subjects bicycle exercise caused greater ventilatory responses and constituted a greater stress in terms of arterial blood pressure and pressure-rate product than did comparable treadmill exercise.

These findings are of clinical importance, as they indicate that in some patients with ischaemic heart disease treadmill exercise may allow achievement of appreciably higher $\mathrm{VO}_{2}$ than does bicycle exercise. This also applies to patients who are limited by angina pectoris, of which the onset is often closely related to a given pressure rate product (Robinson, 1967).

Even at maximal exertion on the treadmill, $\overline{\mathbf{P}}_{\mathrm{SA}}$ may not exceed values measured on the bicycle at relatively low workloads. This can have significant implications with respect to relative hazards in the type of stress testing or exercise conditioning used for older healthy persons or for patients with cardiovascular disease, such as angina pectoris or arterial hypertension. Also a lower arterial pressure for a given aerobic requirement may diminish the frequency and severity of exertional arrhythmias (Gey et al., 1973).

\section{References}

Asmussen, E., and Nielsen, M. (1964). Experiments on nervous factors controlling respiration and circulation during exercise employing blocking of the blood flow. Acta Physiologica Scandinavica, 60, 103.

Åstrand, P.-O., and Saltin, B. (196I). Maximal oxygen uptake and heart rate in various types of muscular activity. fournal of Applied Physiology, 16, 977.

Bruce, R. A. (I97I). Exercise testing of patients with coronary heart disease. Principles and normal standards for evaluation. Annals of Clinical Research, 3, 323.

Bruce, R. A., Kusumi, F., and Hosmer, D. (1973). Maximal oxygen intake and nomographic assessment of functional aerobic impairment in cardiovascular disease. American Heart fournal, 85, 546.

Bruce, R. A., Lind, A. R., Franklin, D., Muir, A. L., MacDonald, H. R., McNicol, G. W., and Donald, K. W. (1968). The effects of digoxin on fatiguing static and dynamic exercise in man. Clinical Science, 34, 29.

Coote, J. H., Hilton, S. M., and Perez-Gonzales, J. F. (1971). The reflex nature of the pressure response to muscular exercise. Fournal of Physiology, 215, 789.

Gey, G. E., Fisher, L. D., Pettet, G. E. M., and Bruce, R. A. (1973). Exertional arrhythmia and nitroglycerin. Fournal of the American Medical Association, 226, 287.

Hermansen, L., Ekblom, B., and Saltin, B. (1970). Cardiac output during submaximal and maximal treadmill and bicycle exercise. Fournal of Applied Physiology, 29, 82.

Hermansen, L., and Saltin, B. (1969). Oxygen uptake during maximal treadmill and bicycle exercise. Fournal of Applied Physiology, 26, 31.

Kusumi, F., Butts, W. C., and Ruff, W. L. (1973). Superior analytical performance by electrolytic cell analysis of blood oxygen content. Fournal of Applied Physiology, 35, 299.

Lind, A. R., Taylor, S. H., Humphreys, P. W., Kenelly, B. M., and Donald, K. W. (1964). The circulatory effects of sustained voluntary muscle contraction. Clinical Science, 27, 229.

McDonough, J. R., Kusumi, F., and Bruce, R. A. (1970). Variations in maximal oxygen intake with physical activity in middle-aged men. Circulation, 41, 743.

Malmborg, R. O. (1965). A clinical and hemodynamic analysis of factors limiting the cardiac performance in patients with coronary heart disease. Acta Medica Scandinavica, 177, Suppl. 426, I.

Miyamura, M., and Honda, Y. (1972). Oxygen intake and cardiac output during maximal treadmill and bicycle exercise. Fournal of Applied Physiology, 32, 185.

Niederberger, M., Bruce, R. A., Frederick, R., Kusumi, F., and Marriott, A. (1974). Reproduction of maximal exercise performance in patients with angina pectoris despite ouabain treatment, Circulation, 49, 309.

Paterson, W. D. (1928). Circulatory and respiratory changes in response to muscular exercise in man. Fournal of Physiology, 66, 323.

Robinson, B. F. (1967). Relation of heart rate and systolic blood pressure to the onset of pain in angina pectoris. Circulation, 35, 1073.

Siegel, W., Gilbert, C. A., Nutter, D. O., Schlant, R. C., and Hurst, J. W. (I972). Use of isometric handgrip for the indirect assessment of left ventricular function in patients with coronary atherosclerotic heart disease. American fournal of Cardiology, 30, 48.

Requests for reprints to Professor Robert A. Bruce, Division of Cardiology, School of Medicine, University of Washington, Seattle, Washington 98195, U.S.A. 